\title{
Advance Industry with Parking-System Using IoT
}

\author{
Dr. Meenu Vijarani
}

\begin{abstract}
Internet of things is latest rapidly growing technology. IOT is the system of interrelated computing devices and objects integrated with electrical devices, applications, sensors, and internet, which allows objects to bring and interchange data. This latest machinery has provided a chance to build advanced industry and its new applications. In this paper, a system is developed that automatically monitor the industry system and generate alert and alarms or take better decisions using concept of IoT. Iot has given us promising way to build powerful industrial systems and program by using smart devices, android applications and sensors.
\end{abstract}

KEYWORDS- IoT, Sensors, Integrated devices, Application

\section{INTRODUTION}

It refers to a technology that can control all industrial devices and appliances on the internet. Here we proposed smart industry with parking system that permits factory member to efficiently control industrial appliances/machines over the internet. Our systems use a microcontroller raspberryPi3 for dealing all needs. This advanced system allows factory managers to automatically gather and study data to make betterinformed decisions and optimize production. The parking system is counter based approach, use sensors to find the number of transport coming and going from factory. It is based counters and have barricade at entrance and exists. The data from sensors is examined and combined with contextual data and shared with authorized members.

\section{GOALS}

The main aim is to make a system which will monitor the systems devices and applications, generate alerts alarms or take intelligent decision using concept of iot. We developed an analytical method to measure the work and execution of advanced factory and parking system which provides more parking spaces for industry vehicle, so vehicles will be well organized and parked.

\section{EXISTING SYSTEM}

In existing system, there is no way to notice unbalaced conditions in industry. A set of instructions are required for observing and checking the progress of factory [1][2]. CCTV used for monitor the only unfavorable but there is no alert and alarms generation. In new system, Alert and alarms will generate as value of data crossed certain approach value.

\section{Manuscript received May 2, 2020}

Dr. Meenu Vijarania, Assistant Professor, Department of Computer Science \&Engineering, Amity University Haryana, Manesar, India (email: mvijarania@ggn.amity.edu)

\section{NEED OF SYSTEM}

The current arrangement of factory is not up to the date, so it is needed to build the intelligent system and also provide the facility parking area for vehicles to upgrade the existing factory and also manage their transport. This system includes the physical objects, technology and network with modern devices according to the purpose and needs. It will help in exploit data and devices to build factories smarter.

\section{OVERVIEW OF SYSTEM}

Advanced industry automation with car parking system consists of sensors (Temperature sensor, LDR sensors, Humidity sensors, Moisture sensors, ultrasonic distance sensors) are used to check the environment and object conditions[3]. Sensors produced analog signal which is provided to android devices. Industry management team set the threshold value for every sensor placed in industry. Android devices check this threshold value send by the sensors. When any un-even conditions occur, devices like (buzzer, Alarm, motor, fan) are used to take accurate measures and alarms and alerts are generated[4]. It will send notifications and mail to the factory management team. Iot helps in many ways to solve the problems. It can be possible through the past experience and similar previous condition stored. It is used to control appliances in factory like intensity of lights, parking door locks, measure oil and water level through a smartphone or web interface. In parking system, when vehicles take entry in parking area he must press the button on the gate and the barrier will open. The entry of each transport is recorded

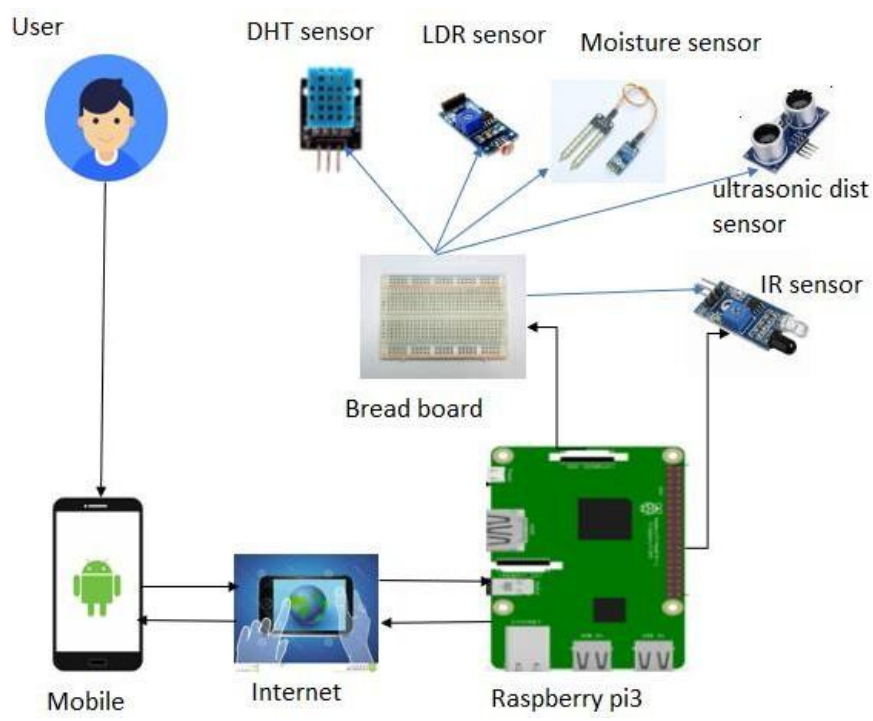

Fig 1: Architecture Diagram 
and if slots is full in parking place, buzzer makes a buzzing sound indicating there is no free space[5,6].

\section{A. Circuit Diagram}

Circuit diagram of advanced industry with parking system consist of many blocks such as raspberryPi, sensors, wifi module, resistor, rheostat, buzzer, capacitor and switch mode power supply and load. In this it is very clear that we have used raspberry pi3 with few components and have power supply of 5 volt and some sensors operate on 3.3 volt, for that we use rheostat to convert the voltage of 5 volt into 3 volts so that some sensors can work properly.

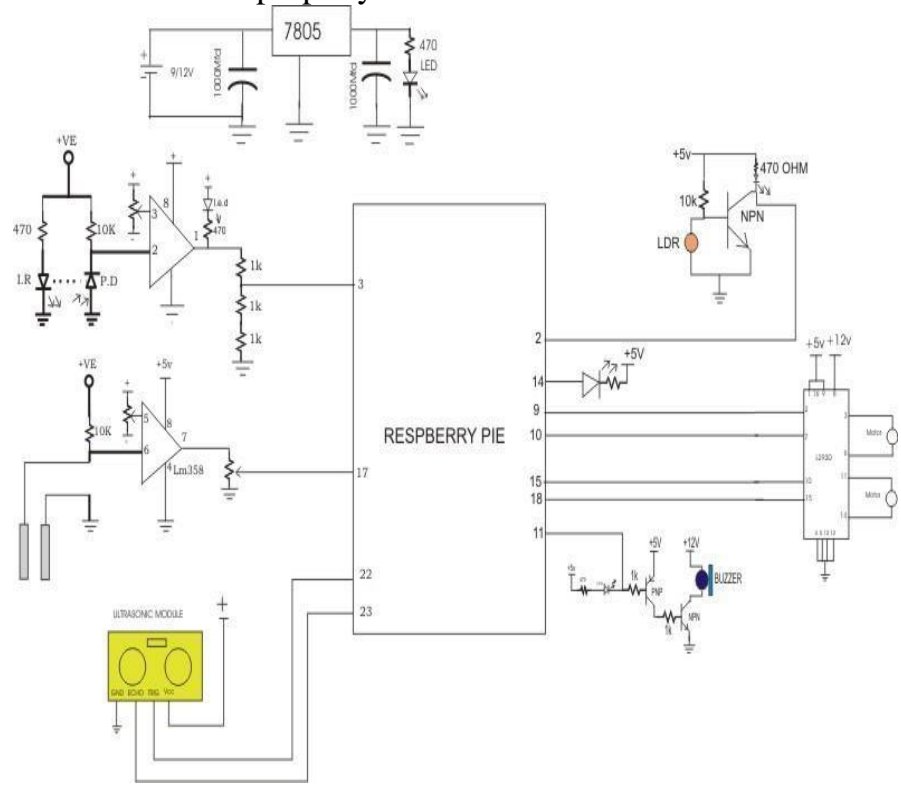

Fig 2: Circuit Diagram

The input pin and output pin if each sensor is linked with specific gpio pins. Memory card is formatted and boot raspbian OS put in to the raspberrypi. A raspberrypi operate on $5 \mathrm{v}$ and linked from system with HDMI cable and laptop is linked with raspberrypi through ethernet cable and do ssh to access into raspberry OS.

\section{B. Working of components}

\section{- Raspberry Pi3}

It is a small computer that allows people to explore computing and learn how to program in language like python. Raspberry looks like a motherboard, with the mounted chips.

There are various components of raspberry pi board.

\section{GPIO}

It is general purpose input/output connections which perform a certain function. Each pin has a different purpose, and send signals.

\section{USB}

Universal-Serial-Bus is a common connection port for peripheral devices of all types (including mouse and keyboard). Model A has 1, and Model B has 2.

\section{HDMI}

High-Definition-Multimedia-Interface connector allows us to connect a high-definition-systems or other compatible device using an HDMI cable.

\section{SD cardslot}

This is a full-sized SD card slot. An SD card with an operating system (OS) installed is required for booting the device.

\section{- Sensors}

Sensors are the important part of the hardware which detects the change in the environment and then report to the server or client regarding to the changes. different sensors are used to monitor the environment of the industry.

\section{DHT sensors}

It is temperature and humidity sensor which is used to examine the temperature and humidity of the factory. If it crosses the threshold value, it will give notifications to the management team.

\section{Moisture sensors}

Moisture sensor can detect rain and check the presence of water in substances of factory. As the moisture sensor come in contact with water and any electricity conducting material it will notify the respective authorities.

\section{DR sensor}

Light Dependent Resistor is a light control device. It is used to measure the amount of light and helps in increasing and decreasing light intensity. It automatically turns on highway light if light is below the certain threshold.

\section{IR sensor}

Infrared radiation used to keep a count of number of workers and vehicles inside the factory at any time. Basically, it detects the motion of object without emitting the IR rays by directly sensing the object from the temperature.

\section{Ultrasonic sensor}

An ultrasonic sensor is a non- contact type of device which is used to measure the distance as well as velocity of an object. In our system, this sensor is used to detect the level of water and oil in tank. It will give notification to authorized team if it crosses the certain level of tank. Basically, it works on the waves of sound, water with greater frequency.

\section{ANALYSIS RESULT}

We have built a prototype for smart factory with car parking system using microcontroller Raspberry Pi3. This advanced system has the following functions.

- The Temperature and humidity level inside the factory have been tracked and monitored. By using DHT sensor gadget will able to show the temperature value along the humidity on real time and both monitored value will be sent to the mobile application with the help of internet.

- Track the water and oil level in machines and also for gas level in the factory working area. alert the disaster management team, if there is any leakage of gas inside the working area.

- IR sensor is used in parking system to count the 
number of vehicles by pressing a button. As button is pressed the entry of vehicle is noted. It is the convenient method for the drivers, they don't need to walk in search of parking spaces.

- For increasing and decreasing the light intensity according to the need if industry, LDR sensor is used to measure the amount of light. It will automatically turn on the highway light. With the help of mobile application (Raspberry, putty), also shows the graph representations of the captured data. The data will be analyzed and monitored will be sent to system of industry with the help of internet. This will make the user to monitor the analyzed data easily.

\section{METHODOLOGY}

Advanced industry with parking system based on iot, design a methodology has following steps.

\section{A. Discover}

It is the first step to find the exact needs and main motive of the system. A problem is clearly mentioned and has all the information which is needed to design a solution to the problem.

\section{B. Design}

After the completing of discovery phase we came to design phase. Keeping all the goals and needs of the system in mind, we design a sample of our system.

\section{Develop}

in the development phase, we implement the logic and ideas drawn up in the design phase. The function of each sensor is figure out according to the industry and its parking system. We programmed the working of each sensor in python language. Architecture of iot based advanced industry automation with smart parking: - here we discuss the high-level architecture for the industry with parking system along with circuit diagram.

\section{Processing unit}

it consists of Raspberry pi, a processor on a chip. It acts like an intermediator between sensors and the raspberrypi. A single raspberrypi have 26 gpio pins. It is essential that the ground of raspberrypi and sensors must be connected in order to exchange data through gpio pins. There is python script running on the chip that check the status of various gpio pins and update his information. Data is stored from various sensors is sent to the raspberrypi through the chip to the devices of industry.

\section{E. Mobile application}

it is the link between the end user and raspbianOS to interact with system. Putty and thingSpeak are used to get the industrial data from the different sensors. This information is used to draw the graph of several modules of smart industry with parking system. The purpose of using this is to create the application that can run on both android and any system with the same source code. In order to ensure proper communication both the raspberry and mobile application must be connected to particular Wi-Fi.

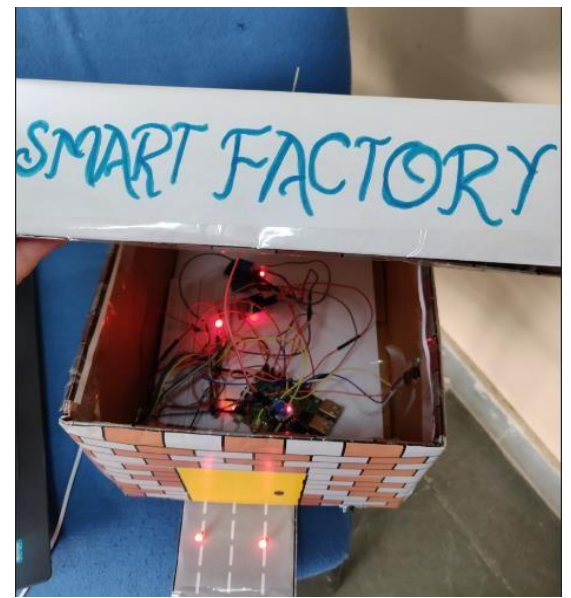

Fig 3: Advanced industry Project Top Side (with Internal Connections and setup)

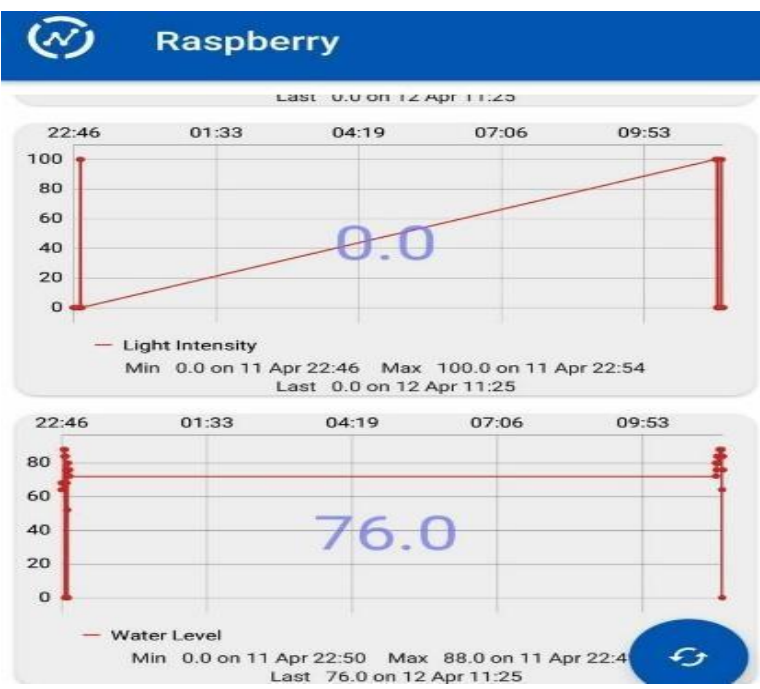

Fig 4: Graph of light intensity and water level

\section{(v) Raspberry}

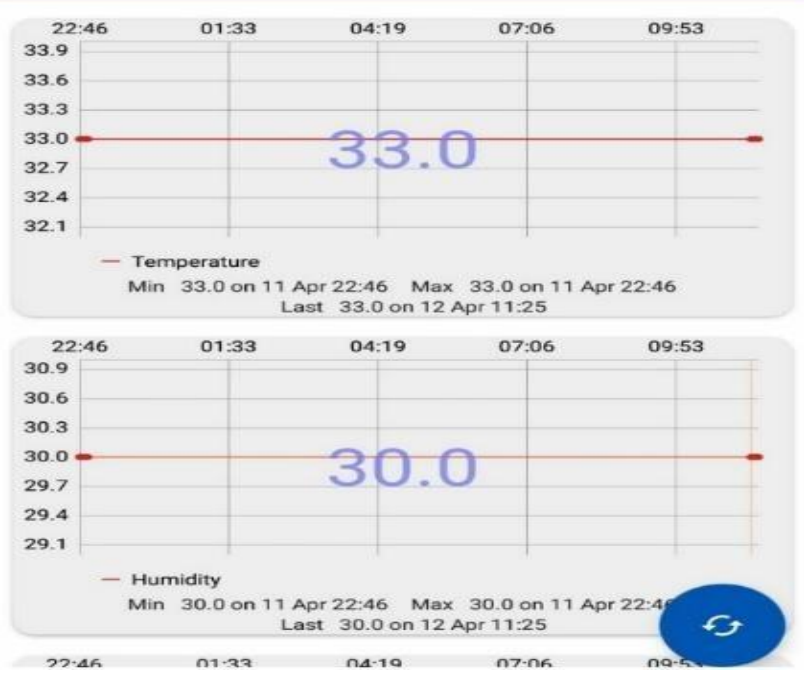

Fig 5: Graph of light intensity and water 


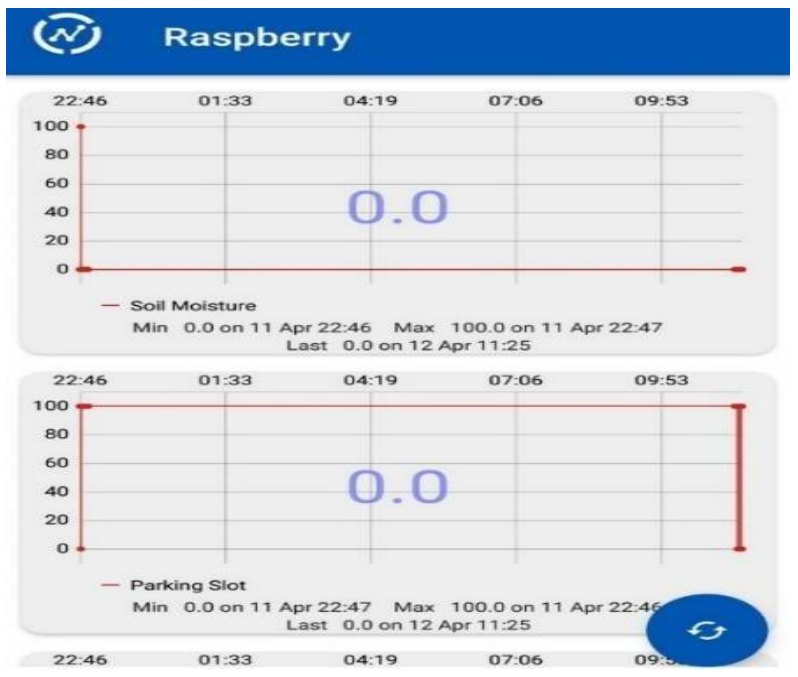

Fig 6: Graph of soil moisture and parking slot.

\section{Channel Stats}

Created: adelagex

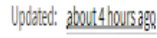

Lastentor, about thoussag

Enties:24
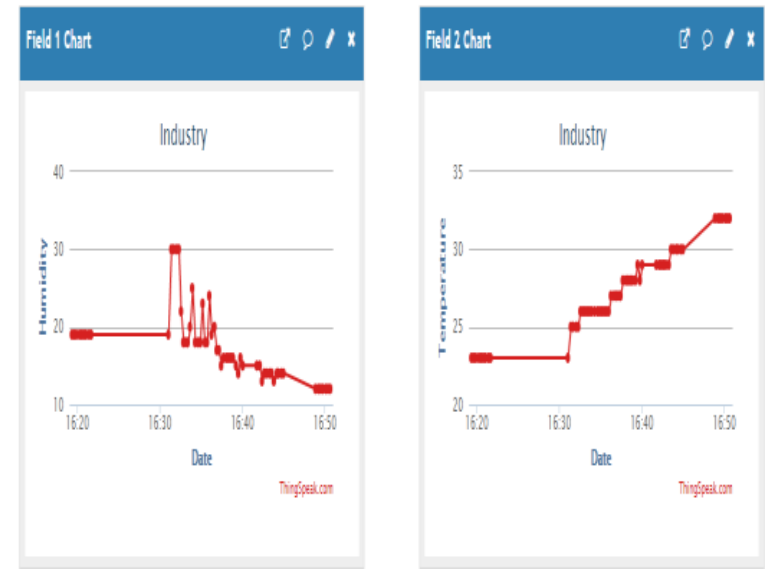

Fig 7: Humidity and Temperature graph that can be accessed viaThing Speak

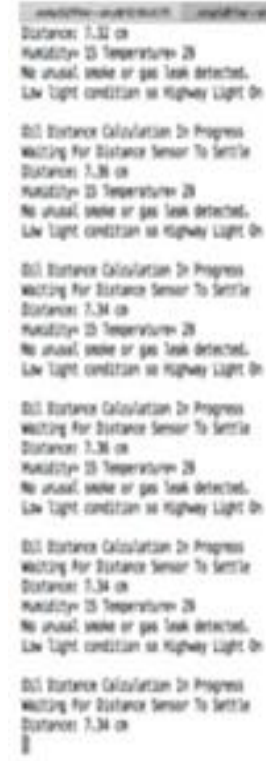

Fig: 8: Output of main Python Script that monitors sensors

\section{CONCLUSION}

Internet-of-technology is the today's technology which is expanding everyday and the time is not that much faraway when projects like advanced automated-cities will take place in India like UAE. So, focusing on all this in brain this smart- industry shows many advanced system in today's technical world and it have the possibility and scope of I.o.T is end-less and it can serve for any greater development. Smart-factory environments incorporate many frameworks which are different, and are practiced by different genus. The principle benefaction of this plank is to provide a conceptualization for the performance \& utilization of technology ie: Smart-industry amenity gadgets, which manifests the implementing of the smart gadgets into the actual enviro- nment of industry.

\section{REFERENCES}

[1] Li Da Zu" Internet of Things in Industries: A Survey" IEEE Transactions on Industrial Informatics, vol. 10, no. 4, November 2014

[2] Sadeque Reza Khan Professor Dr. M. S. Bhat "GUI Based Industrial Monitoring and Control System IEEE paper, 2014

[3] Ayman Sleman and Reinhard Moeller "Integration of Wireless Sensor Network Services into other Home and Industrial networks "IEEE paper

[4] S.d.t. Kelly, n.k. Suryadevara and S.C. Mukhopadhyay Towards the Implementation of IoT for Environmental Condition Monitoring in Homes,IEEE Paper 2013

[5] Jinsung Byun, Insung Hong, Byoungjoo Lee, and Sehyun Park, Member Intelligent Household LED Lighting System Considering Energy Efficiency and User Satisfaction,IEEE paper February 2013

[6] Gopinath Shanmuga Sundaram, Bhanuprasad Patibandala, Harish Santhanam Bluetooth Communication using a Touchscreen Interface with the Raspberry Pi 978-14799-0053-4/13/31.00 2013 IEEE

[7] Shopan Dey, Ayon Roy, Sandip Das(2016) "Home 
Automation Using Internet of Thing”, IEEE 7th Annual Ubiquitous Compu- ting,

[8] Electronics \& Mobile Communication Conference (UEMCON),pp.15-20

[9] Jasmeet Chhabra, Punit Gupta (2016),'IoT based Smart Office Design using Power and Security Management", 1st International Conference on Innovation and Challenges in Cyber Security (ICICCS),pp. 209-213

[10]Luca Mainetti, Vincenzo Mighali, Luigi Patrono,(2015)" An IoT- based User-centric Ecosystem for Heterogeneous Smart factory Environments", IEEE ICC SAC-Internet of Things, pp. 1-10.

[11] $\mathrm{Li}(2014)$, "A novel de sign for a comprehensive smart au-tomation system for the office environment", Emerging Technol- ogy and Factory Automation (ETFA), IEEE, pp. 80-85

[12]R. Bhuyar and S. Ansari, "Design and implementation of smart office automation system," International Journal of Computer Applications, vol. 151, no. 3, pp. 37-42, 102016.

[13] S. Kejriwal and S. Mahajan, "Smart buildings: How iot technology aims to add value for real estate companies," Deloitte Center for Financial Services, New York, NY, USA, Tech. Rep., 2016. 